\title{
Use of Waste Plastic in Flexible Pavements-Green Roads
}

\author{
Yash Menaria1, Rupal Sankhla ${ }^{2}$ \\ ${ }^{1}$ Poornima Institute of Engineering and Technology, Jaipur, India \\ ${ }^{2}$ Centre for Environmental Planning \& Technology, Ahmedabad, India \\ Email: yash07menaria@gmail.com, rupal.sankhla71@gmail.com
}

Received 24 June 2015; accepted 6 September 2015; published 9 September 2015

Copyright (C) 2015 by authors and Scientific Research Publishing Inc.

This work is licensed under the Creative Commons Attribution International License (CC BY). http://creativecommons.org/licenses/by/4.0/

c) (i) Open Access

\section{Abstract}

Wrappers of betel nuts, chocolates, chips, hand bags, cold drink bottles and all other forms of plastic create significant environmental and economic problem. They consume massive energy and other natural resources, depleting the environment in various ways. In manufacturing firms, construction industries and products delivery services, use of plastic is a priority to handle and pack things comfortably due to its light weight, cost effectiveness and strength. Plastics cannot be banned as it will result in usage of natural resources like paper, wood at a great extent. It is made up of various chemical elements and is regarded as a highly pestilent material which does not easily degrade in the natural environment after its usage. Waste plastics are made up of Polyethylene, Polystyrene and Polypropylene. Temperature varying between $120^{\circ} \mathrm{C}-160^{\circ} \mathrm{C}$ gives the softening point of these plastics [5]. They do not produce any toxic gases during heating but the softened plastics have tendency to form a lamination or coating over the aggregate, when it is sprayed over the hot aggregate at $160^{\circ} \mathrm{C}$. The main objective of this paper is to discuss the significance of plastic in terms of cost reduction, increase in strength and durability when these plastics are heated and coated upon the aggregates $\left(160^{\circ} \mathrm{C}\right)$ to compensate the air voids with plastic and binds with aggregate to provide stability.

\section{Keywords}

Municipal Plastic Waste, Aggregates, Shredded Plastic, Stripping, Marshel Stability, Optimum Bitumen Content, Flexible Pavement

\section{Introduction}

Plastic is everywhere in today's lifestyle and its disposal is a great problem. It is a non-biodegradable product 
due to which these materials pose environmental pollution and problems like breast cancer, reproductive problems in humans and animals and genital abnormalities [2].

If a ban is put on the use of plastics on emotional grounds, the real cost would be much higher, the inconvenience much more, the chances of damage or contamination much greater... Hence the question is not "plastics vs no plastics" but it is more concerned with the judicious use and re-use of plastic-waste.

Both the issues when taken together lead to a single solution that we can use this waste plastic in Flexible Pavements in such a manner that it gets coated over the surface of aggregate by heating $\left(140^{\circ} \mathrm{C}-160^{\circ} \mathrm{C}\right)$ because plastics like PE, PS, PP used in PET Bottles, disposal glasses, handbags, covers of various appliances etc. soften up to $160^{\circ} \mathrm{C}$. The experiments conducted in the laboratory depict fruitful results can substantially increase the stability and durability of roads plus, making it a very effective step towards eco-friendliness compared to conventional and traditional techniques of flexible pavements construction.

\subsection{Literature Review}

Since many years the utilization of plastic in flexible pavements has been done to increase the stability, durability of roads and reduce the cost of construction of roads by replacing some percentage of bitumen with that of the waste plastic. The LDPE can only be used in this technique as it gets softened at the desired temperature i.e., $160^{\circ} \mathrm{C}$ and coated over the aggregates. There is no modification in the plant is required because plastic is mixed at the same time when aggregates are poured into Hot Mix Plant for 30 - 50 secs, hence no fuel consumption takes place. There is a consistent research still going on to attain the optimality and many have stated to use the plastic in road construction [8].

Prof. C.E.G Justo states that addition of $8 \%$ percent by weight of processed plastic is desirable in saving $0.4 \%$ bitumen by weight of mix [4].

Dr. R. Vasudevan has also stated that use of waste plastic in bitumen increase the binding property as compared to the conventional bitumen [3]. It improves the properties of bitumen resulting in increase in Softening Point and decrease in Penetration value thus improving the durability [6].

\subsection{Objectives of the Study}

Basic intention is to efficiently utilize the waste plastic in constructive way so that it can be beneficial to society. Main objectives of current project work are:

1) To identify the optimum proportion of waste plastic to be added in the bitumen mix for getting the required strength.

2) To compare the experimented results with the conventional pavement details and perform the economic analysis.

3) To prepare statistical model for optimum utilisation of plastic waste.

\subsection{Experimental Programme}

\subsubsection{Materials and Its Physical Properties}

Bitumen-VG-30 penetration grade bitumen was used for the present study. Table 1 shows the test results and permissible limits of the tests carried out to check the physical properties of bitumen.

Aggregates: $20 \mathrm{~mm}, 10 \mathrm{~mm}, 6 \mathrm{~mm}$ and stone dust were used for the present study whose sieve analysis is shown in Table 2.

Table 3 shows the test results and permissible limits of the tests carried out to check the physical properties of aggregates.

Aggregate Gradation DBM-II (50 - 75 Mm Thickness): Grading of the aggregates is done in the DBM layer as shown in Figure 1.

\subsubsection{Process [7]}

DRY PROCESS (Lab test-D.B.M II Grade)

1) Plastic wastes are cleaned and dried (For ex: disposed carry bags, glasses etc) with a thickness of 60 microns is shredded into small pieces (2.36 mm - $4.75 \mathrm{~mm}$ size).

2) Aggregate are weighed as shown in Figure 2 and are heated to $160^{\circ} \mathrm{C}$ in a pan. 
Table 1. Physical properties of bitumen as IS 73:1992 [1].

\begin{tabular}{cccc}
\hline DESIGNATION & TEST RESULT & PERMISSIBLE LIMIT & TEST METHOD \\
\hline Specific gravity of bitumen & 1.025 & $0.99 \mathrm{~min}$ & IS: $1202-1978$ \\
Softening point of bitumen & $54.35^{\circ} \mathrm{C}$ & $47^{\circ} \mathrm{C}(\mathrm{min})$ & IS: $1205-1978$ \\
Flash point of bitumen & $272^{\circ} \mathrm{C}$ & $220{ }^{\circ} \mathrm{C}(\mathrm{min})$ & IS: $1209-1978$ \\
Fire Point of Bitumen & $300^{\circ} \mathrm{C}$ & $270{ }^{\circ} \mathrm{C}(\mathrm{min})$ & IS: $1209-1978$ \\
Bitumen Penetration Test & $50 \mathrm{~mm}$ & $45(\mathrm{~min})$ & IS: $1203-1978$ \\
Ductility test & $94 \mathrm{~cm}$ & 100 & IS: $1208-1978$ \\
\hline
\end{tabular}

Table 2. Sieve analysis.

\begin{tabular}{ccccc}
\hline SIEVE SIZE & UPPER LIMITS & LOWER LIMITS & MID LIMITS & RESULTS \\
\hline 37.5 & 100 & 100 & 100 & 100.00 \\
26.5 & 100 & 90 & 95 & 100.00 \\
19 & 95 & 71 & 83 & 93.89 \\
13.2 & 80 & 56 & 68 & 71.29 \\
4.75 & 54 & 38 & 46 & 42.69 \\
2.36 & 42 & 28 & 35 & 29.41 \\
0.3 & 21 & 7 & 14 & 10.53 \\
0.075 & 8 & 2 & 5 & 4.18 \\
\hline
\end{tabular}

Table 3. Aggregate test results.

\begin{tabular}{cccc}
\hline DESIGNATION & TEST RESULT & $\begin{array}{c}\text { PERMISSIBLE LIMIT } \\
\text { (MORTH SPECIFICATION) }\end{array}$ & TEST METHOD \\
\hline Aggregate Impact Value Test & 23.80 & Max 30\% $\%$ IS: 2386 Part IV \\
Specific Gravity of Aggregates $(20 \mathrm{~mm})$ & 2.68 & - & IS: 2386 Part III \\
Specific Gravity of Aggregates $(10 \mathrm{~mm})$ & 2.71 & IS: 2386 Part III \\
Specific Gravity of Aggregates $(6 \mathrm{~mm})$ & 2.69 & IS: 2386 Part III \\
Specific Gravity of Aggregates (stone dust) & 2.74 & $5 \%$ & IS: 2386 Part III \\
Stripping Value of Aggregates & $45 \%$ & Physical appearance \\
Water Absorption & 0.40 & Max 2\% & IS: 2386 Part III \\
\hline
\end{tabular}

\section{DBM}

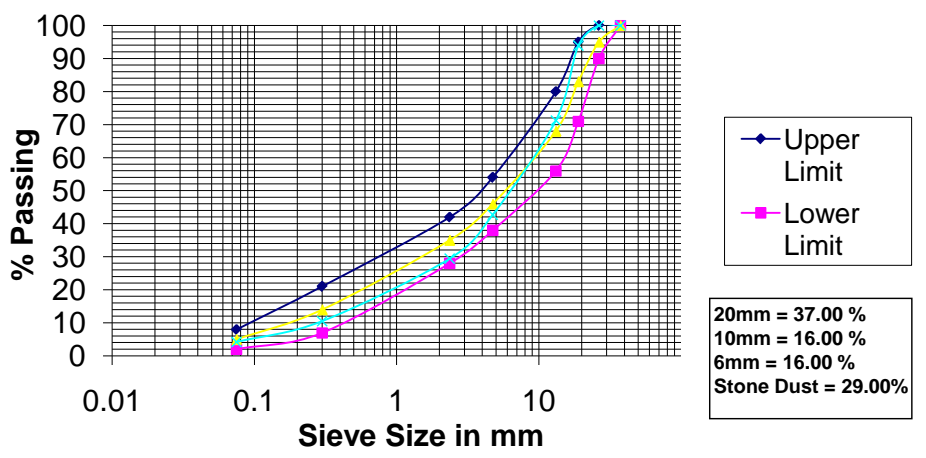

Figure 1. Aggregate gradation. 
3) Shredded plastic as shown in Figure 3 is added to the hot mix. The plastic gets softened and coated over the surface of the aggregate in 30 - 60 seconds as shown in Figure 4.

4) Hot Bitumen (heated up to a maximum of $160^{\circ} \mathrm{C}$ ) is added immediately and the contents are mixed thoroughly.

5) As the plastics are heated to a maximum temperature of $165^{\circ} \mathrm{C}$, there is no evolution of any gas as shown in the above Table 4 . When heated above $270^{\circ} \mathrm{C}$, the plastics get decomposed and above $750^{\circ} \mathrm{C}$ they get burnt and produce harmful noxious gases.

6) The moulds are preheated as shown in Figure 5 and then the mix is poured in the preheated moulds as shown in Figure 6.

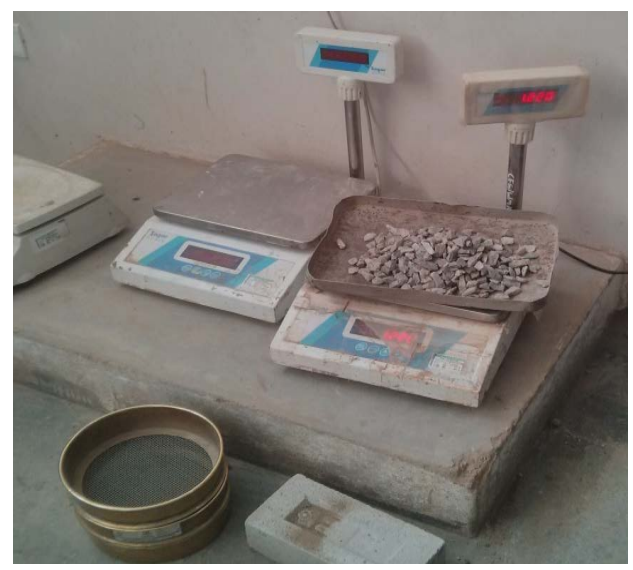

Figure 2. Aggregate weighing.

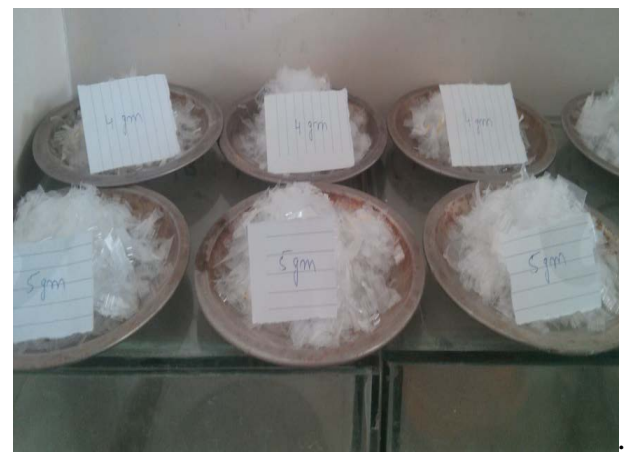

Figure 3. Shredded plastic.

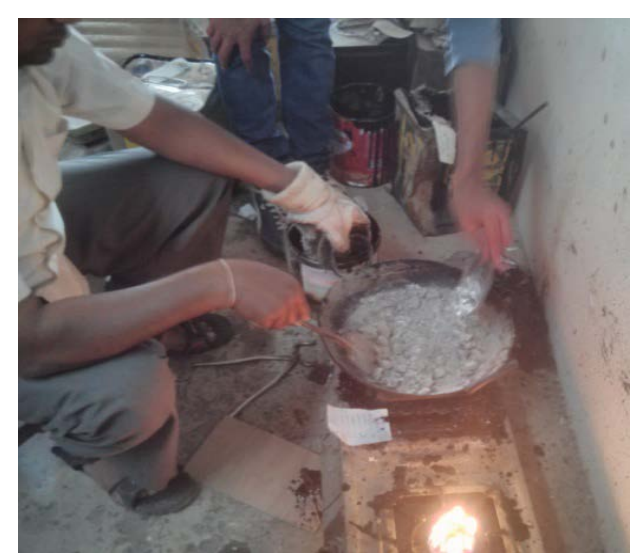

Figure 4. Adding shredded plastic to aggregates. 


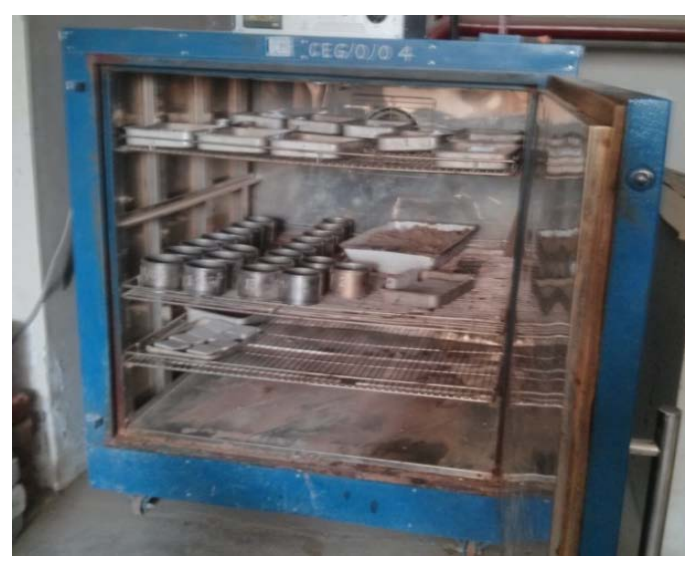

Figure 5. Pre heating of moulds.

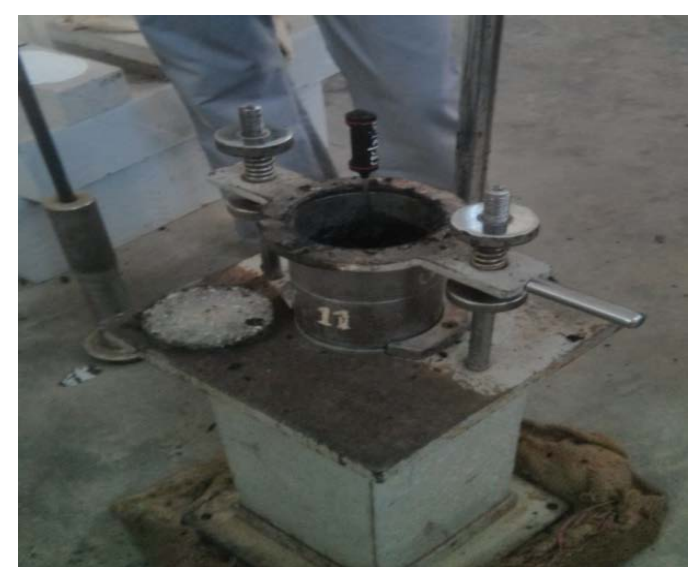

Figure 6. Mould filling.

Table 4. Characteristics of waste plastic [9].

\begin{tabular}{|c|c|c|c|c|}
\hline Polymer & Softening Temp. $\left({ }^{\circ} \mathrm{C}\right)$ & Products Reported & Decomposition Temp. $\left({ }^{\circ} \mathrm{C}\right)$ & Examples \\
\hline Polyethylene (PE) & $100-120$ & No gas & $270-350$ & $\begin{array}{c}\text { Bags, sacks, } \\
\text { detergent bottles etc. }\end{array}$ \\
\hline Polypropylene (PP) & $140-160$ & No gas & $270-300$ & $\begin{array}{l}\text { Film wrapping of } \\
\text { biscuits, chips }\end{array}$ \\
\hline Polystyrene (PS) & $110-140$ & No gas & $300-350$ & Disposable glasses \\
\hline
\end{tabular}

7) The moulds are marked as shown in Figure 7 and kept for 24 hours in air and weighed.

8) Then the prepared moulds as shown in Figure 8 are poured in water and weight of SSD (saturated surface dry sample) is taken.

9) Then after SSD weight, samples are kept in $60^{\circ} \mathrm{C}$ hot water bath and then tested for Marshall Stability and Flow value just after taking out from water bath as shown in Figure 9.

The results and analysis mentioned below are attained by considering D.B.M Grade IIratio of aggregates and VG-30 grade Bitumen whose minimum value of bitumen that should be taken according to I.S code is $4.25 \%$.

Firstly, conventional moulds are tested at $4.25 \%, 4.5 \%, 4.75 \%$ and the optimum solution is obtained at $4.5 \%$ as shown in Table 5.

Thus taking optimum reading into consideration and varying \% of Plastic in Bitumen (4.50\%) at $0 \%$, $8 \%$, $10 \%, 12 \%, 14 \%$, the results are as follows:

Conventional moulds are tested at $4.25 \%, 4.5 \%, 4.75 \%$ and the optimum solution is obtained at $4.5 \%$. Therefore the characteristic values of the specimens at $4.5 \%$ bitumen content are shown in Table 6 . 


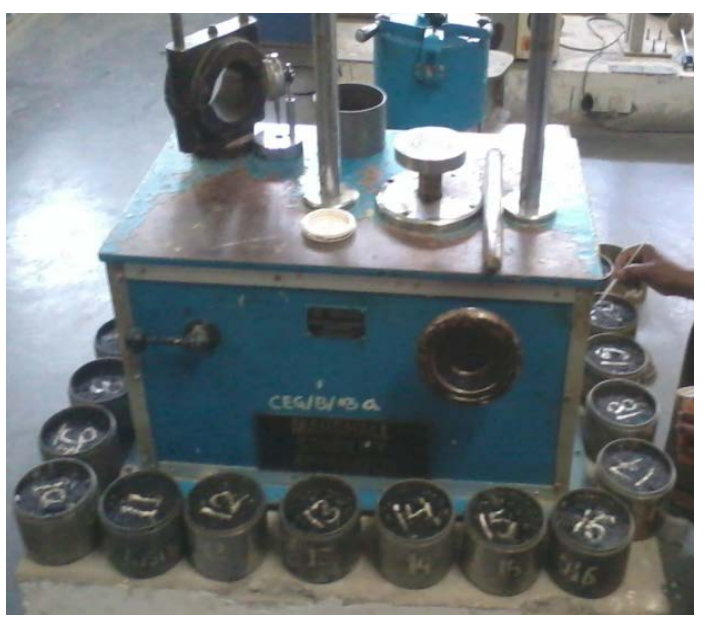

Figure 7. Marking of prepared moulds.

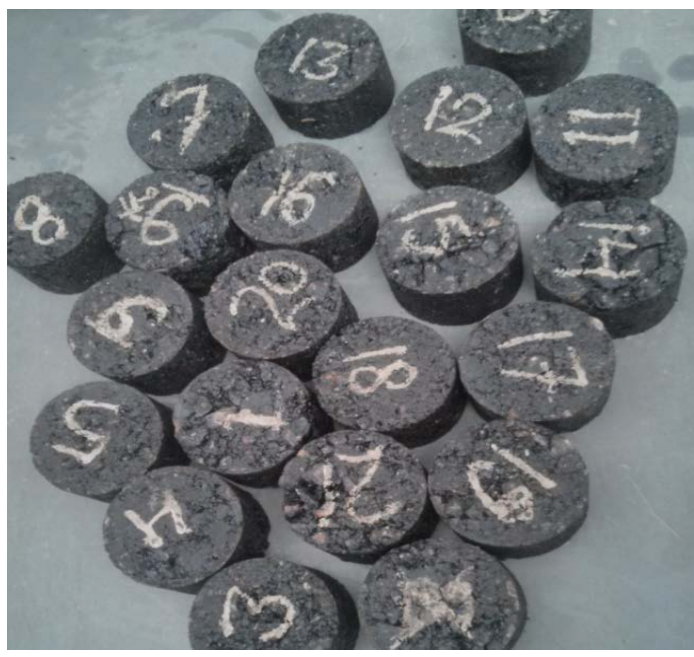

Figure 8. Prepared specimens.

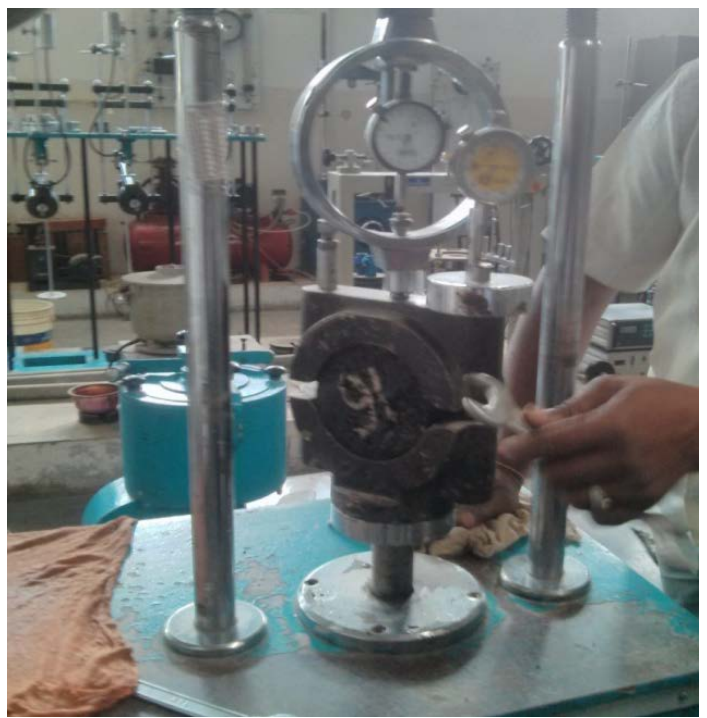

Figure 9. Performing marshal stability test. 
Table 5. Characteristic values at different bitumen contents.

\begin{tabular}{|c|c|c|c|c|c|}
\hline Mould no & Bitumen content & Stability (kg) & Average stability (kg) & Flow value (mm) & $\begin{array}{l}\text { Avg. Flow value } \\
(\mathrm{mm})\end{array}$ \\
\hline 1 & & 822 & & 2.8 & \\
\hline 2 & $4.25 \%$ & 931.6 & 822 & 3 & 2.93 \\
\hline 3 & & 712.4 & & 3 & \\
\hline 4 & & 822 & & 4 & \\
\hline 5 & $4.50 \%$ & 1013.8 & 949.87 & 2.4 & 3.26 \\
\hline 6 & & 1013.8 & & 3.1 & \\
\hline 7 & & 685 & & 3.2 & \\
\hline 8 & $4.75 \%$ & 808.3 & 785.67 & 3.4 & 3.17 \\
\hline 9 & & 863.1 & & 3.2 & \\
\hline
\end{tabular}

Table 6. Characteristic values of the specimens at $4.5 \%$ bitumen content.

\begin{tabular}{cccccccc}
\hline \multirow{2}{*}{ MOULD NO } & $\begin{array}{c}\text { BITUMEN } \\
\text { CONTENT }\end{array}$ & $\begin{array}{c}\text { PLASTIC } \\
\text { CONTENT (\%) }\end{array}$ & STABILITY (KG) & $\begin{array}{c}\text { FLOW VALUE } \\
(\mathrm{MM})\end{array}$ & $\begin{array}{c}\text { VA } \\
(\%)\end{array}$ & $\begin{array}{c}\text { VMA } \\
(\%)\end{array}$ & $\begin{array}{c}\text { VFB } \\
(\%)\end{array}$ \\
\hline 1 & 0 & 1098 & 2.8 & 4.5 & 15.5 & 71.2 \\
2 & 6 & 861 & 2.77 & 3.9 & 15.2 & 72.2 \\
3 & & 9 & 2.6 & 4.5 & 15.6 & 71.2 \\
4 & 10 & 1005 & 2.87 & 5.6 & 16.5 & 66.1 \\
5 & 12 & 1059 & 3.23 & 5.9 & 16.8 & 64.8 \\
6 & 14 & 966 & 3.5 & 7.2 & 18 & 59.8 \\
LIMIT AS PER MORTH SPECIFICATIONS & 900 & $2-4$ & $3-6$ & & $65-75$ \\
\hline
\end{tabular}

\subsection{Data Collection}

Characteristics Curves Based on Experiments Conducted in Lab for D.B.M II Grade (4.5\% Net Content of Bitumen and Plastic)

1) Figure 10 shows the plot between \% plastic in bitumen and Stability (KN).

2) Figure 11 shows the bar graph between \% Air Voids (Va) and \% of plastic in bitumen.

3) Figure 12 shows the bar graph between Bulk Density (gm/cc) and \% Plastic in bitumen.

4) Figure 13 shows the plot between Flow value (mm) and \% of Bitumen Content.

5) Figure 14 shows the plot between \% Voids filled with Bitumen (VFB) and \% plastic content.

\subsection{Analysis}

\subsubsection{Economic Analysis per Km of Flexible Pavement (Dbm)}

A huge quantity of plastic waste has been used as modifying agents. However, the high cost of these polymers compared to bitumen means that the amount of polymer needed to improve pavement performance should be as small as possible. This major restriction could be avoided by using waste materials like plastics. From an environmental and economic standpoint, the use of waste plastic as a bitumen-modifying agent may contribute to solving a waste disposal problem and to improving the quality of road pavements. Table 7 shows the economic analysis of pavement and the total savings due to use of plastic waste.

\subsubsection{SPSS Analysis}

SPSS model is used for the optimum utilisation of plastic waste. One way Annova test is carried out keeping the plastic content as independent variable and stability, air voids, bulk density, flow value and VFB as dependent variables. Figure 15 shows the analysis sheet to input the variables. 


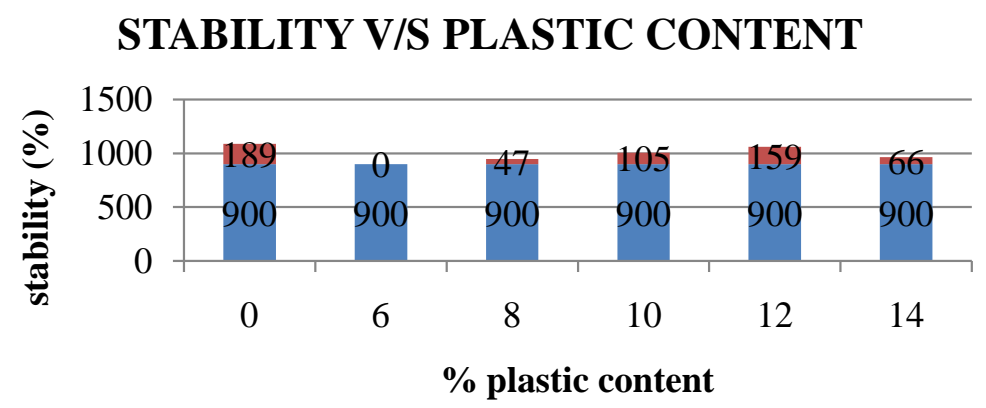

Figure 10. \% Plastic in bitumen and stability (KN).

Air void V/S plastic content

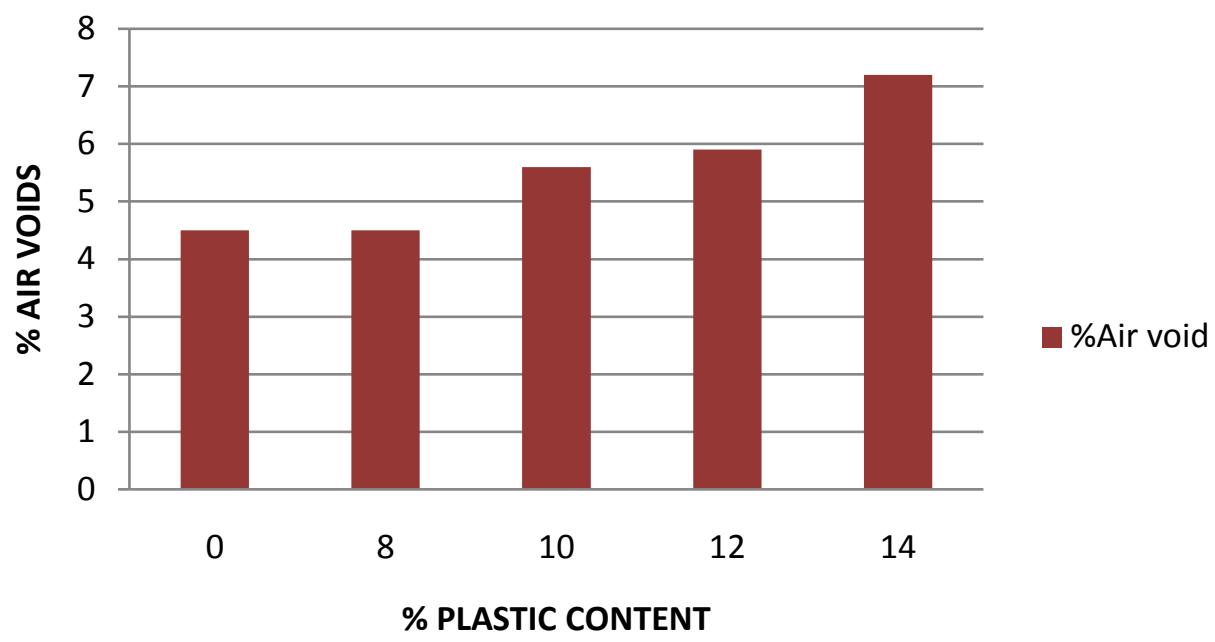

Figure 11. \% Air Voids (Va) and \% of plastic.

\%of plastic in bitumen v/sBulk density, Gb

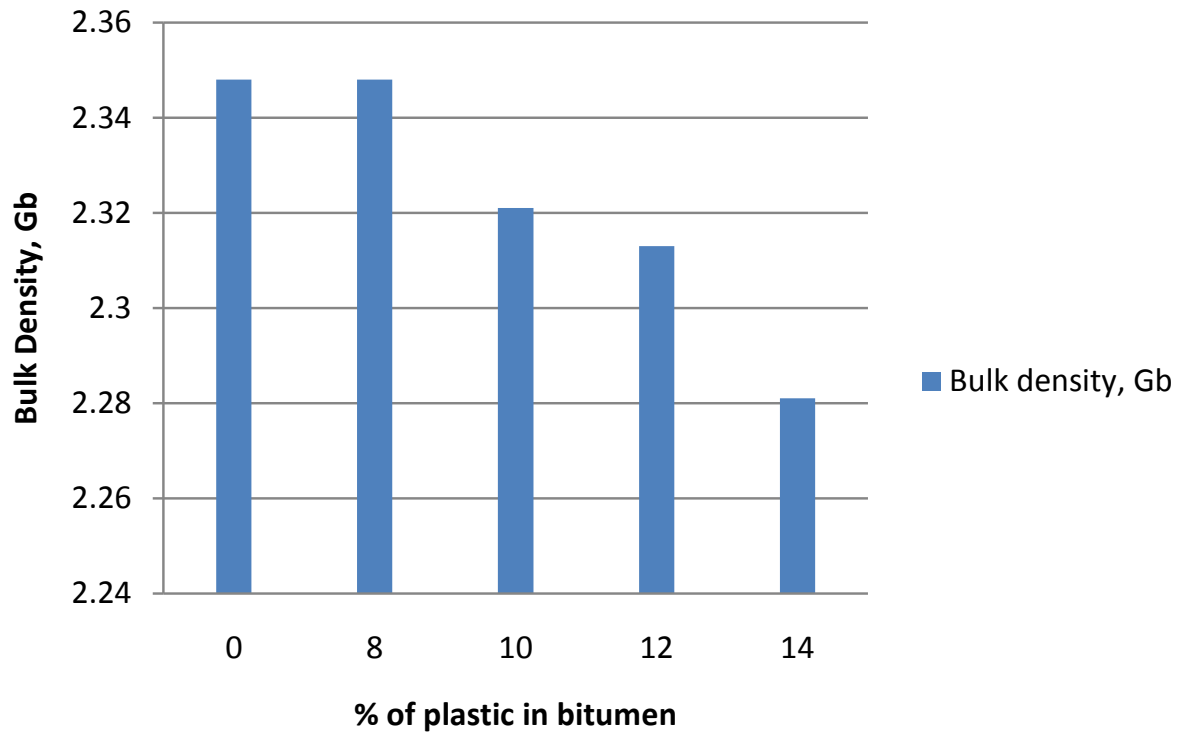

Figure 12. Bulk density (gm/cc) and \% plastic in bitumen. 


\section{FLOW VALUE v/s PLASTIC CONTENT}

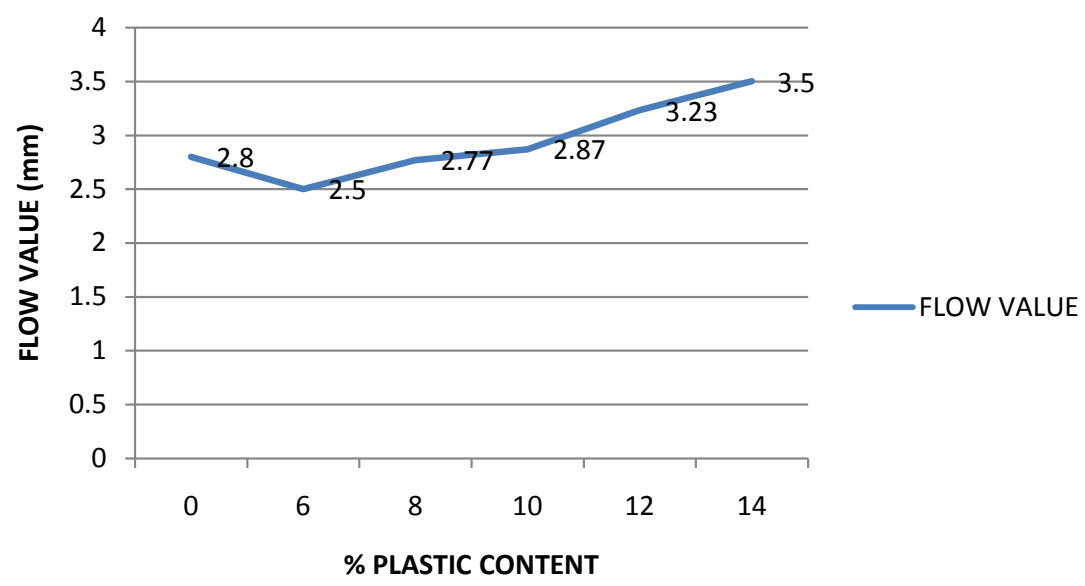

Figure 13. Flow value (mm) and \% of bitumen content.

\section{VFB $\mathrm{v} / \mathrm{s}$ plastic content}

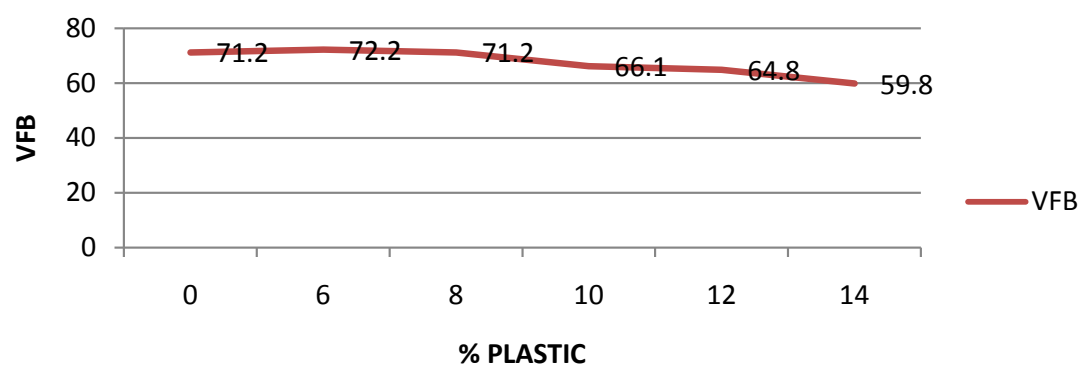

Figure 14. \% Voids filled with bitumen (VFB) and \% plastic content.

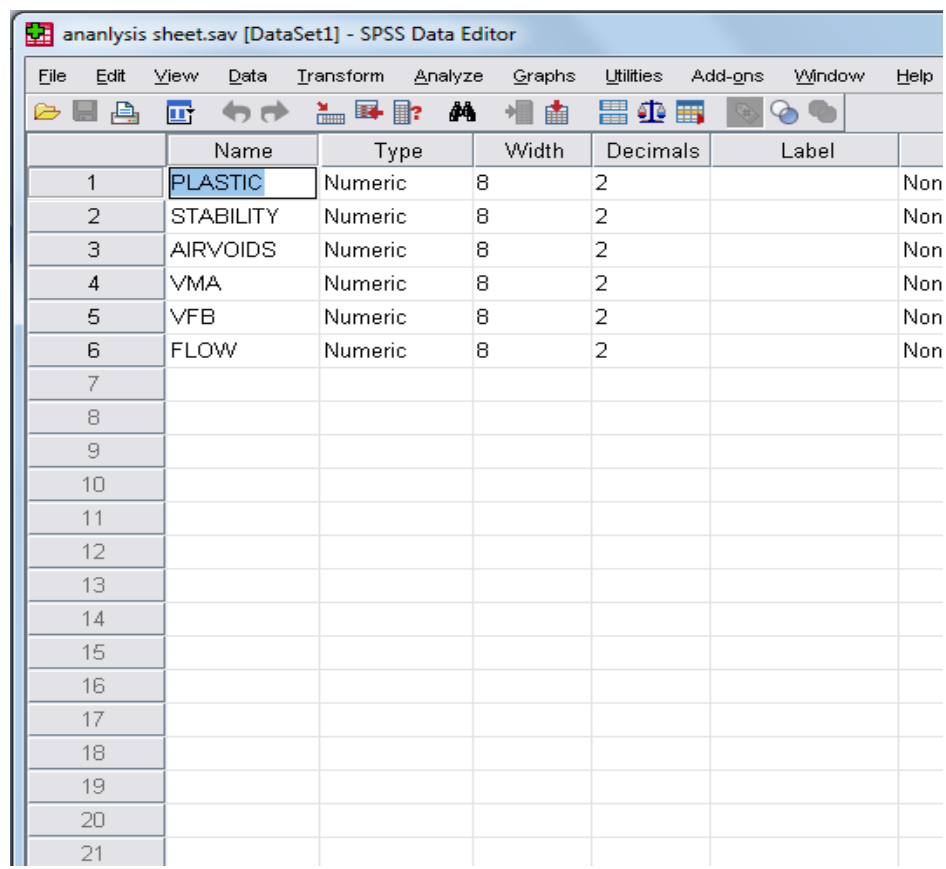

Figure 15. Analysis sheet. 
a) Figure 16 shows the SPSS window carrying out one way annova test, keeping plastic content as independent factor and air voids in dependent list.

b) Figure 17 shows the SPSS window carrying out one way annova test, keeping plastic content as factor and stability in dependent list.

c) Figure 18 shows the SPSS window carrying out one way annova test, keeping plastic content as factor and flow in dependent list.

d) Figure 19 shows the SPSS window carrying out one way annova test, keeping plastic content as factor and VFB in dependent list.

e) Figure 20 shows the SPSS window carrying out one way annova test, keeping plastic content as factor and VMA in dependent list.

\section{Results and Discussion}

1) Utilisation of waste plastic improves the binding property of mix.

2) The optimum result of waste plastic came out to be $8 \%$ from the experiments conducted.

3) The properties of bitumen such as penetration, softening point improved with the addition of the waste fibre.

4) Plastic roads can also be constructed in the areas having high temperatures $\left(50^{\circ} \mathrm{C}\right)$.

5) Waste plastic in roads increases the stability value and durability to a great extent.

Table 7. Economic analysis table.

\begin{tabular}{cc} 
DESCRIPTION & RS \\
\hline total cost of 1 km road of 3.75 m width (DBM LAYER) \\
Savings in bitumen due to addition of plastic waste: \\
Cost of Bitumen saved (1704 Kg. equivalent to plastic used) & $2,109,050$ \\
Eliminating the need of Anti-stripping agent: cost savings in anti stripping agent \\
total cost of 1 km road of 3.75 m width (WITH PLASTIC) \\
Total Minimum Assured Savings per km & 85,200 \\
\hline
\end{tabular}

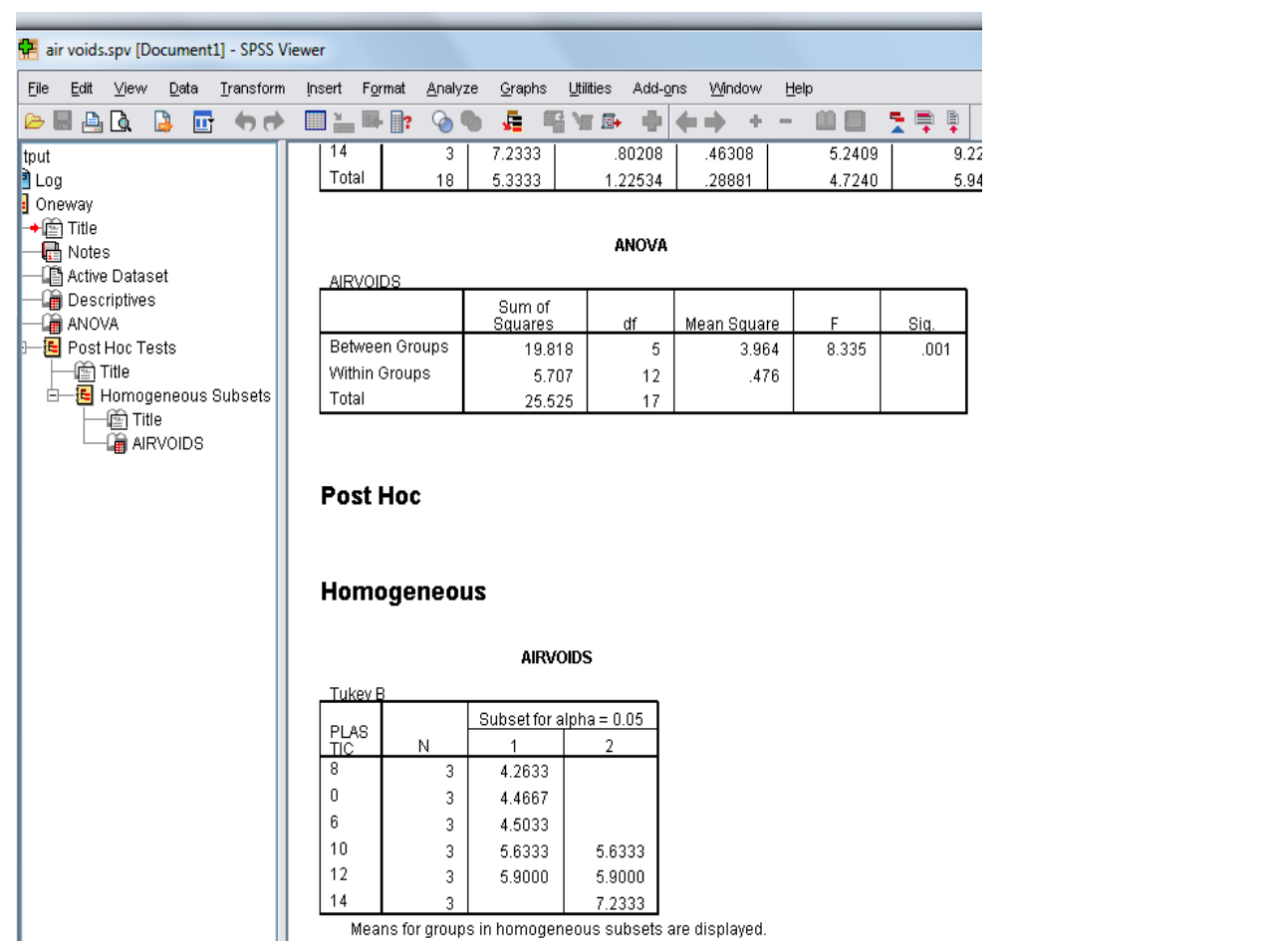




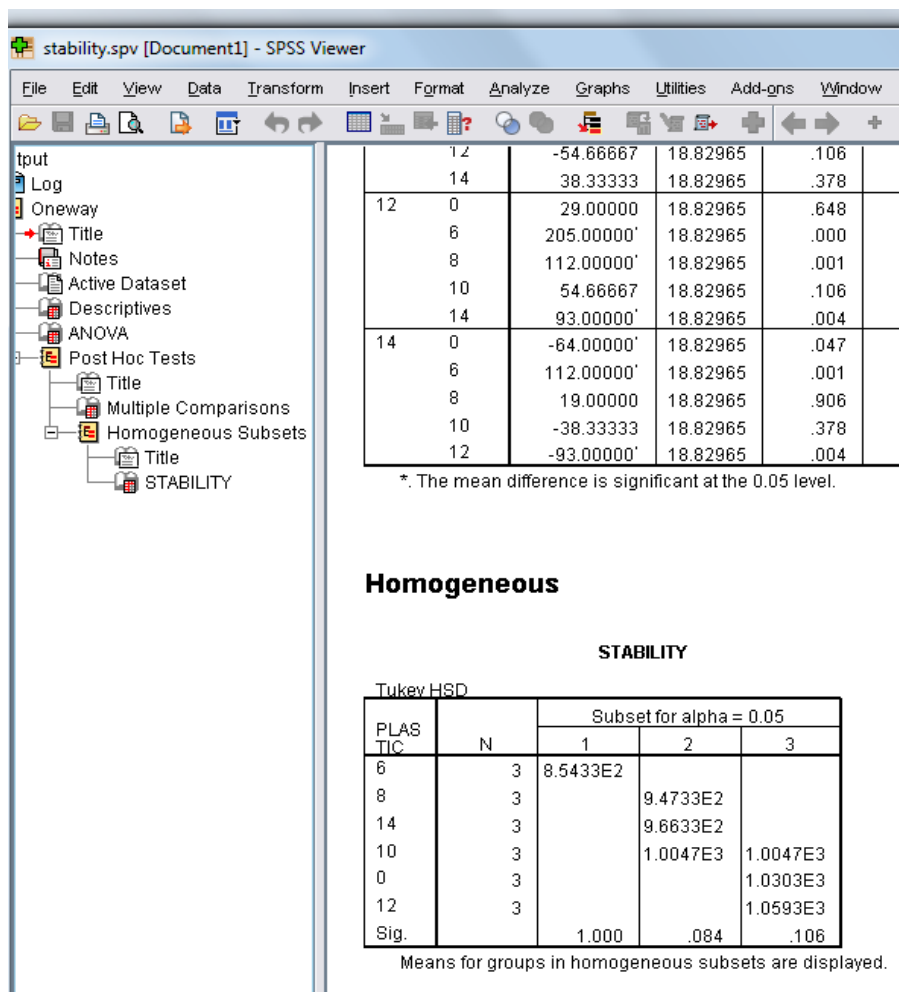

Figure 17. SPSS analysis.

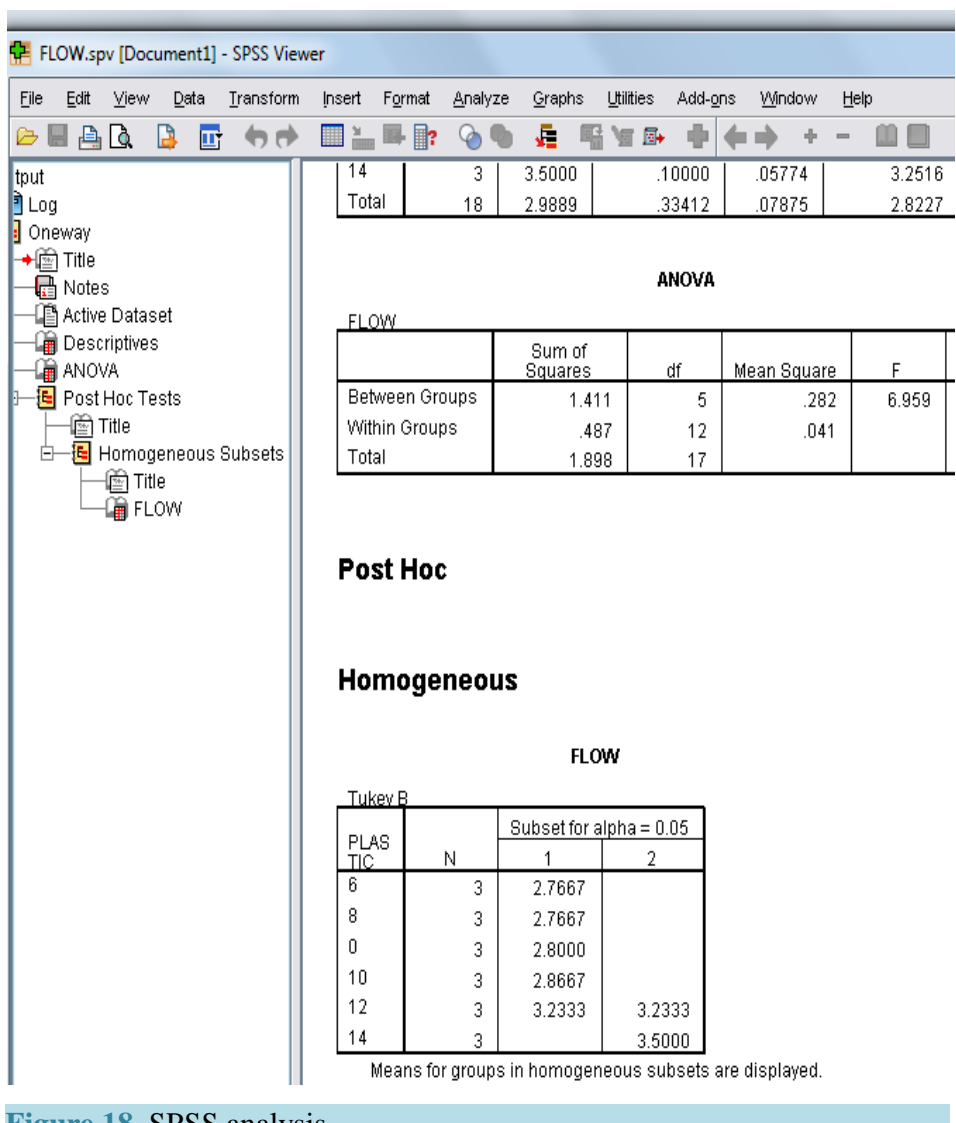

Figure 18. SPSS analysis. 


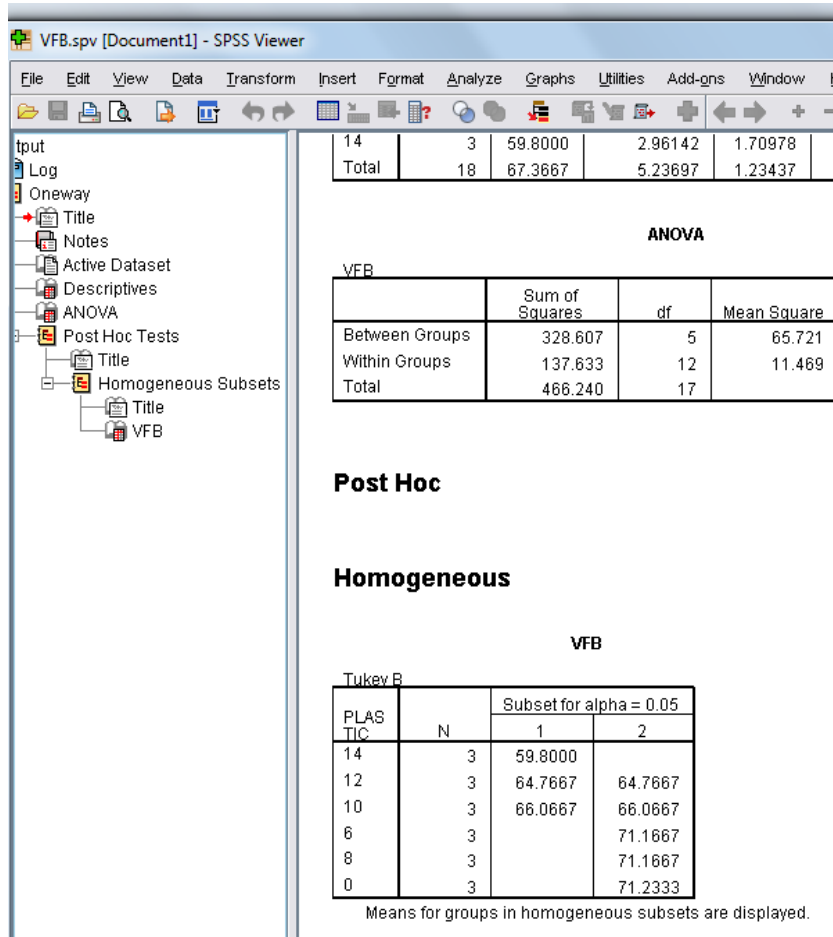

Figure 19. SPSS analysis.

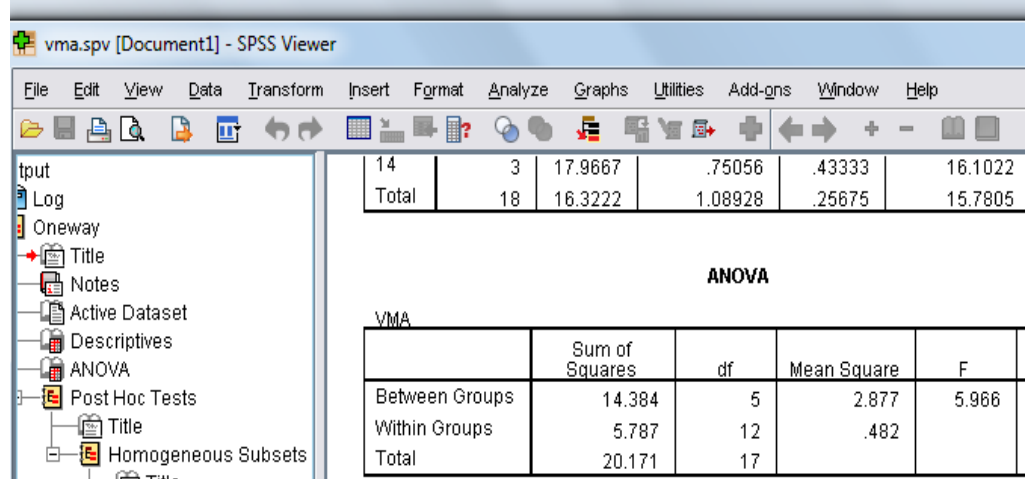

\section{Post Hoc}

\section{Homogeneous}

\section{VMA}

Tukev
\begin{tabular}{|l|r|c|c|}
\hline \multirow{2}{*}{ PLAS } & & \multicolumn{2}{|c|}{ Subset for alpha $=0.05$} \\
\cline { 3 - 4 } TIC & $N$ & 1 & 2 \\
\hline 0 & 3 & 15.5000 & \\
6 & 3 & 15.5667 & \\
8 & 3 & 15.5667 & \\
10 & 3 & 16.5333 & 16.5333 \\
12 & 3 & 16.8000 & 16.8000 \\
14 & 3 & & 17.9667 \\
\hline
\end{tabular}
Means for groups in homogeneous subsets are displayed.

Figure 20. SPSS analysis. 
6) This technique is very eco-friendly as it uses the waste plastic which is being disposed in oceans, landfills etc.

7) Replacement of bitumen with plastic reduces the cost of construction significantly.

8) When durability and stability of roads will improve, then its future maintenance cost will be saved too.

\section{References}

[1] Guidelines for the Use of Plastic Waste in Rural Roads Construction by Dr. V. Vasudevan, TEC, Madurai, and CRRI, New Delhi. National Rural Roads Development, Agency Ministry of Rural Development.

[2] Verma, S.S. (2008) Roads from Plastic Waste. The Indian Concrete Journal, November, 43-44.

[3] Rajasekaran, S., Vasudevan, R. and Paulraj, S. (2013) Reuse of Waste Plastics Coated Aggregates-Bitumen Mix Composite for Road Application-Green Method. American Journal of Engineering and Research, 2, 1-13.

[4] Justo, C.E.G. and Veeraragavan, A. (2002) Utilization of Waste Plastic Bags in Bituminous Mix for Improved Performance of Roads. Banglore University, Bengaluru.

[5] Swami, V., et al. (2012) Use of Waste Plastic in Construction of Bituminous Roads. International Journal of Engineering Science and Technology (IJEST), 4, 2351-2355.

[6] Punith, V.S (2010) Study of the Effect of Plastic Modifier on Bituminous Mix Properties.

[7] Bale, A.S. (2011) Potential Reuse of Plastic Waste in Road Construction: A Review. International Journal of Advances in Engineering \& Technology (IJAET), 2, 233-236.

[8] Vasudevan, R., Nigam, S.K., Velkennedy, R., Ramalinga, A., Sekar, C. and Sundarakannan, B. (2007) Utilization of Waste Polymers for Flexible Pavement and Easy Disposal of Waste Polymers. Proceedings of the International Conference on Sustainable Solid Waste Management, Chennai, 5-7 September 2007, 105-111.

[9] Gawande, A., Zamre, G.S., Renge, V.C., Bharsakalea, G.R. and Tayde, S. (2012) Utilization of Waste Plastic in Asphalting of Roads. Scientific Reviews \& Chemical Communications, 2, 147-157. 